\title{
Sarcococca Blight: Use of Whole-Genome Sequencing for Fungal Plant Disease Diagnosis
}

Martha Malapi-Wight, United States Department of Agriculture-Agriculture Research Service (USDA-ARS), Systematic Mycology and Microbiology Laboratory, Beltsville, MD 20705; Catalina Salgado-Salazar, USDA-ARS, Systematic Mycology and Microbiology Laboratory; and Department of Plant Biology and Pathology, Rutgers University, New Brunswick, NJ 08906; Jill E. Demers, USDA-ARS, Systematic Mycology and Microbiology Laboratory; David L. Clement, University of Maryland Home and Garden Information Center, Ellicott City, MD 21042; Karen K. Rane, Plant Diagnostic Laboratory, University of Maryland, College Park 20742; and Jo Anne Crouch, USDAARS, Systematic Mycology and Microbiology Laboratory

\begin{abstract}
Malapi-Wight, M., Salgado-Salazar, C., Demers, J. E., Clement, D. L., Rane, K. K., and Crouch, J.A. 2016. Sarcococca blight: Use of whole-genome sequencing for fungal plant disease diagnosis. Plant Dis. 100:1093-1100.

Early and accurate diagnosis of new plant pathogens is vital for the rapid implementation of effective mitigation strategies and appropriate regulatory responses. Most commonly, pathogen identification relies on morphology and DNA marker analysis. However, for new diseases, these approaches may not be sufficient for precise diagnosis. In this study, we used whole-genome sequencing (WGS) to identify the causal agent of a new disease affecting Sarcococca hookeriana (sarcococca). Blight symptoms were observed on sarcococca and adjacent Buxus sempervirens (boxwood) plants in Maryland during 2014. Symptoms on sarcococca were novel, and included twig dieback and dark lesions on

leaves and stems. A Calonectria sp. was isolated from both hosts and used to fulfill Koch's postulates but morphology and marker sequence data precluded species-level identification. A 51.4-Mb WGS was generated for the two isolates and identified both as Calonectria pseudonaviculata. A single-nucleotide polymorphism at a noncoding site differentiated between the two host isolates. These results indicate that the same C. pseudonaviculata genotype has the ability to induce disease on both plant species. This study marks the first application of WGS for fungal plant pathogen diagnosis and demonstrates the power of this approach to rapidly identify causal agents of new diseases.
\end{abstract}

Early and accurate disease diagnosis plays a vital role in plant protection, enabling rapid and appropriate regulatory response and the implementation of effective mitigation practices. Diagnosis of fungal pathogens is primarily achieved through visual examination of disease symptoms, pathogen morphology, sequencing of housekeeping genes, physiological tests, serological tests, and targeted DNA-based assays, either independently, or in some combination depending on the pathosystem (Miller et al. 2009). Macro- and microscopic examinations of fungal morphology are the simplest and most widely used approaches, and are employed on a routine basis by plant health practitioners and regulatory agencies, and in plant diagnostic clinics. Unfortunately, morphology alone may not always yield clear-cut diagnoses. As fungi are increasingly defined on the basis of unique molecular signatures rather than visual characteristics, it becomes progressively more difficult for pathologists, clinicians, regulators, and others responsible for routine pathogen diagnosis to render precise identification. Fungal taxonomists continue to use molecular signatures to expand and alter species boundaries across several major groups of important plant pathogens, including the genera Alternaria,

Corresponding author: J. A. Crouch; E-mail: joanne.crouch@ars.usda.gov

The mention of firm names or trade products does not imply that they are endorsed or recommended by the United States Department of Agriculture (USDA) over other firms or similar products not mentioned. The USDA is an equal opportunity provider and employer.

Current address of M. Malapi-Wight: USDA Animal and Plant Health Inspection Service, Plant Germplasm Quarantine Program, Beltsville, MD 20705.

*The $\boldsymbol{e}$-Xtra logo stands for "electronic extra" and indicates that two supplementary figures are published online.

Accepted for publication 29 January 2016.

http://dx.doi.org/10.1094/PDIS-10-15-1159-RE

(C) 2016 The American Phytopathological Society
Bipolaris, Colletotrichum, and Fusarium; the Magnaporthales family; Mycospherella spp.; and countless others, improving diagnostic capacity by increasing our ability to recognize discrete pathogens (Crouch et al. 2009a, 2009c; Crous 2009; Damm et al. 2009; Lawrence et al. 2013; Luo et al. 2015; Manamgoda et al. 2014; O'Donnell et al. 2004; Weir et al. 2012; Zhang et al. 2011). Yet, routine diagnoses of these fungi in the clinical or regulatory setting may still be elusive, because it is now difficult or even impossible to discriminate species without multilocus marker sequencing or the use of custom diagnostic assays. At the same time, if pathogen identifications enabled through molecular phylogenetics are not facilitated through user-friendly analytic protocols, routine disease diagnostic applications are hindered rather than enhanced.

Single marker-based molecular approaches can provide greater sensitivity and specificity than morphology-based methods, and translate better to the diagnostic laboratory setting than multilocus phylogenetics; however, in practice, these too may pose difficulties. Molecular work may be precluded due to inadequate laboratory facilities, equipment, or staffing. Examples include port entry points, remote or outlying research stations, or even state-of-the-art diagnostic laboratories where high volumes of sample submissions, available staff, or budgetary constraints preclude costly and time-consuming DNA and RNA work. Even for well-equipped laboratories, modern molecular diagnostics are constrained by the use of targeted amplification-based technologies, in the form of either polymerase chain reaction (PCR) or isothermal reactions. Specific oligonucleotides and control reagents need to be readily available in the laboratory based on a priori expectations, a requirement that may not always be easily met. The inevitable appearance of a novel pathogen is an obvious example of an instance where the target cannot be defined in advance, and where the specificity of targeted amplification may be detrimental. Maintaining an inventory of reagents and controls for all known pathogens encountered in diagnostic laboratories is largely impractical. This is especially true for technologies such as real-time PCR that utilize expensive fluorescent-labeled oligonucleotides and require panels of control reagents or organisms that may not be readily available for purchase. In contrast, for molecular 
markers where so-called "universal" primers are used, the investment is nominal, and it is easy to have a panel of the most common PCR primer sets on hand. Indeed, nucleotide sequences from defined marker regions such as the ribosomal DNA internal transcribed spacer (ITS) are routinely used for pathogen identification (Bellemain et al. 2010). However, many of the markers that provide amplification targets across large organismal groups are not informative for diagnostics. The ITS region is the most well-known example but this marker cannot consistently differentiate between species or genotypes, isolates, or pathovars; these distinctions may correspond to profoundly different virulence or pathogenicity traits (Crouch et al. 2009b; Gehesquière et al. 2016; Harder et al. 2013; Luo et al. 2015; Manamgoda et al. 2014; O'Donnell et al. 2004). Furthermore, DNAbased assays may be biased if they are developed based on an incomplete pathogen sampling, resulting in assays that may not detect novel and important genotypes or pathovars. This is always the case when dealing with entirely novel pathogens.

High-throughput next-generation sequencing (NGS) is a promising technology for diagnostic applications, circumventing many of the difficulties presented by standard amplification-based molecular tools. In contrast to traditional molecular diagnostics that are reliant on amplification or sequencing of predefined targets, NGS requires no previous knowledge of the pathogen. The entire sample of DNA or RNA may be sequenced without the use of specific primers and often in the absence of a PCR amplification process. NGS technology has quickly become a routine diagnostic tool for identification of genetic variants associated with human diseases such as cancer, Down syndrome, autism, epilepsy, and schizophrenia (Visscher et al. 2012). Application of NGS for microbial pathogen diagnosis is also gaining popularity in medical and veterinary settings, including diagnoses of extended-spectrum $\beta$-lactamaseproducing Escherichia coli, identification of the novel dairy cattle Schmallenberg virus, and discrimination of human respiratory viral pathogens (Hoffmann et al. 2012; Sherry et al. 2013; Thorburn et al. 2015). In the field of plant pathology, virologists routinely utilize NGS to identify uncultured viruses directly from environmental samples (Adams et al. 2009; Barba et al. 2014; Boonham et al. 2014; Kehoe et al. 2014; MacDiarmid et al. 2013). However, for fungal pathogens, the use of whole-genome sequencing (WGS) as an independent diagnostic tool has never been reported, possibly due to the relatively greater size and complexity of fungal genomes (average 19 to $280 \mathrm{Mb}$ ) (Raffaele and Kamoun 2012). To date, a few studies have pioneered the use of NGS as the basis for diagnostic tool development for bacterial, fungal, and oomycete plant pathogens but the resultant assays were dependent on primed amplification reactions or species-specific probes rather than direct diagnoses from the sequence data (Ash et al. 2014; Bühlmann et al. 2013).

In this study, we made use of NGS to aid in the characterization of a new disease affecting Sarcococca hookeriana (sarcococca or Himalayan sweet box), a small, shade-loving evergreen shrub that produces fragrant white flowers. A member of the Buxaceae family, this species is increasingly popular in landscape plantings because, unlike many other shade-loving ornamentals, it is virtually pest free and is not a preferred host for deer browsing. In September 2014, novel disease symptoms were observed on newly installed sarcococca plants in a residential landscape in Baltimore County, MD. In the same landscape bed, several boxwood plants (Buxus sempervirens; Buxaceae) showed blight disease symptoms. Visual inspection revealed the presence of Calonectria fungi but it was unclear whether the two hosts were infected with the same organism. We used this novel disease outbreak on sarcococca as an opportunity to use NGS technology as a method to rapidly identify the two pathogens, and to determine whether their molecular signatures could provide information about the source of the infections. Our objectives in this research were to (i) use NGS to generate whole-genome datasets for the Calonectria sp. collected from infected sarcococca and boxwood plants from the same location, (ii) determine the sequence of marker regions for identification to the species-level using multilocus sequence typing, and (iii) compare the two host isolates to look for any genetic changes that may be responsible for the apparent shift in host range. This work demonstrates how NGS can be used to identify and quickly characterize plant pathogens inducing new diseases, in addition to generating other useful data on the biology of the pathogen.

\section{Materials and Methods}

Fungal isolates and morphological assessments. Fungi were isolated from boxwood and sarcococca plants showing disease symptoms by placing symptomatic leaves and stems in a moist chamber at $22^{\circ} \mathrm{C}$ for 2 days under continuous light. Conidia and conidiophores were collected using sterile forceps and placed on V8 agar plates (V8 juice at $200 \mathrm{ml} \mathrm{liter}^{-1}, \mathrm{CaCO}_{3}$ at $3 \mathrm{~g} \mathrm{liter}^{-1}$, and agar at $20 \mathrm{~g} \mathrm{liter}^{-1}$ ) amended with neomycin and streptomycin (each at $0.3 \mathrm{~g} / \mathrm{liter}$; Sigma-Aldrich, St. Louis). Axenic cultures of Calonectria fungi isolated from sarcococca and boxwood plants were submitted to the The Centraalbureau voor Schimmelcultures (CBS) Fungal Biodiversiry Centre, an institute of the Royal Netherlands Academy of Arts and Sciences (KNAW) (Utrecht, The Netherlands) under the accession numbers CBS 139394 and CBS 139395, respectively.

Morphological structures were assessed from fungal colonies growing on potato dextrose agar (PDA; Fisher Scientific, Pittsburg). Petri plates were incubated with a 12-h day-and-night cycle for the required time to observe sporulation (5 to 8 days). Growth rates and colony characteristics were obtained from $1 \times$ PDA plates inoculated with mycelium plugs ( $4 \mathrm{~mm}$ in diameter) and incubated at $20^{\circ} \mathrm{C}$. Color terminology was based on Rayner (1970). Morphological characteristics were determined by mounting fungal structures in $3 \% \mathrm{KOH}$ solution. Microscopic observations were performed on a Zeiss Axioscope 2 (Carl Zeiss Microscopy GmbH, Jena, Germany), with differential interference contrast illumination. Measurements of continuous characteristics (diameter of vesicle and length and width of stipes, conidiophores, and conidia) were made using the Zen Pro Software (v.2; Zeiss Corporation, Oberkochen, Germany) and based on 30 units per structure. Size values are reported as ranges (maximum and minimum) followed by average values.

For scanning electron microscopy (SEM) images, boxwood leaves (B. sempervirens var. joy) inoculated with CBS 139394 or CBS 139395 were assessed. Fifteen individual leaves were inoculated with each fungal isolate by submersion in a conidia suspension $\left(10^{5}\right.$ spores $\left.\mathrm{ml}^{-1}\right)$ for $10 \mathrm{~min}$. Leaves were incubated in a clean wet chamber at $20^{\circ} \mathrm{C}$ under a 12-h day-and-night cycle for 5 days. Leaves with fungal structures on the surface were mounted onto a specimen holder and transferred to the TM3030 Table Top SEM microscope (Hitachi High-Technologies Corporation, Tokyo). Fungal morphological features were observed at a working distance of approximately $9 \mathrm{~mm}$ at low-vacuum mode $(15.0 \mathrm{kV})$. Images were magnified $\times 1,000$ with built-in software (TM3030 v01-02).

Plant inoculations. 'Fragrant Valley' S. hookeriana plants were collected from a botanical garden in Montgomery County, MD, then potted in 7.5-liter containers in a soil-based medium and maintained in a growth chamber at $20^{\circ} \mathrm{C}$ under $12 \mathrm{~h}$ of light. These plants had been maintained without fungicide applications for more than 5 years in the botanical garden prior to removal for this study. Plants were maintained in the growth chamber for 1 week before inoculations were performed. Fungal inoculum was produced by subculturing CBS 139394 isolated from sarcococca onto 0.5× PDA. Plates were maintained for 4 weeks in a growth chamber at $20^{\circ} \mathrm{C}$ with $12 \mathrm{~h}$ of light. To induce sporulation, the procedure of Dart and Hong (2013) was followed. Spore suspensions were normalized to $4.4 \times$ $10^{4}$ spores $\mathrm{ml}^{-1}$ and sprayed to runoff onto five individual plants within one pot. Five plants in a separate pot were sprayed to runoff with sterile deionized (DI) water to serve as a control. Both pots were enclosed in separate plastic bags to maintain humidity and leaf wetness for 3 days, and maintained in a growth chamber at $20^{\circ} \mathrm{C}$ under $12 \mathrm{~h}$ of light. After plastic bags were removed, plants were misted daily with sterile DI water to maintain leaf wetness and humidity for 7 days, then examined for lesion development.

DNA sequencing using Sanger and Illumina technologies. For genomic DNA (gDNA) extractions, conidia were harvested with sterile DI water from V8 agar plates and inoculated in medium 
consisting of yeast extract at $3 \mathrm{~g} \mathrm{liter}^{-1}$, peptone at $10 \mathrm{~g} \mathrm{liter}^{-1}$, and dextrose at $20 \mathrm{~g} \mathrm{liter}^{-1}$. Samples were incubated at $22^{\circ} \mathrm{C}$ with constant shaking and harvested at 5 days postinoculation (dpi). DNA extractions were performed as previously reported (Malapi-Wight et al. 2015). Final DNA quantities were determined using the Qubit 2.0 fluorometer (Life Technologies, Grand Island, NY).

For Sanger sequencing of the TUB2 marker, a portion of the TUB2 gene was PCR amplified from CBS 139394 and CBS 139395 with the primer set $\mathrm{Bt} 2 \mathrm{a} / \mathrm{Bt} 2 \mathrm{~b}$ following published protocols (Glass and Donaldson 1995). PCR products were cleaned with ExoSap-IT (Affymetrix, Santa Clara, CA) before sequencing. Sanger cycle sequencing reactions were performed with the BigDye Terminator v3.1 cycle sequencing kit (Life Technologies). Sequencing was performed on an Applied Biosystems 3130xl Genetic Analyzer (Life Technologies), with $2 \times$ coverage.

DNA libraries for whole-genome shotgun sequencing on the Illumina platform were generated for CBS 139394 and CBS 139395 using the TruSeq DNA PCR-Free sample preparation kit (Illumina, Inc.), as previously reported (Malapi-Wight et al. 2015). Briefly, libraries were prepared from gDNA sheared to $550 \mathrm{bp}$ using the Covaris M220 ultrasonicator (Covaris, Inc., Woburn, MA). Library quantification and quality assessments were performed using the LabChipXT DNA 750 (Caliper Life Sciences, Hopkinton, MA), Qubit 2.0 fluorometer (Life Technologies), and QIAxcel Advanced (Qiagen, Germantown, MD). After normalization, libraries were sequenced as $2 \times 300$ paired end reads in two independent runs on an Illumina MiSeq instrument using the MiSeq v3 kit 600-cycle cartridges (Illumina, Inc.).

De novo genome sequence assembly and analysis. Illumina sequence reads were analyzed using CLC Genomics Workbench (version 7.5.1; CLC Bio, Boston). Prior to assembly, reads were trimmed to remove Illumina adapters and barcodes. Nucleotide sites with lowquality Phred scores (below 0.05), and reads $<30$ bp were discarded. Reads from isolate CBS 139394 collected from diseased sarcococca was used for the de novo genome assembly and served as the reference sequence for subsequent analyses. De novo genome assembly was performed using the CLC Genomics de Bruijn graphs algorithm (kmer size $n=51$ and bubble size $=50$ ), with contigs below $500 \mathrm{bp}$ discarded. Gene predictions were performed from the CBS 139394 assembly using AUGUSTUS v3.0.2 (Stanke et al. 2008), with Fusarium graminearum serving as the gene model. Genome completeness was assessed from the assembly using CEGMA c2.4, which relies on Markov models to determine the presence of a set of 248 core eukaryotic genes from the dataset (Parra et al. 2007). For the identification of variant nucleotide sites between isolate CBS 139394 and CBS 139395 , the Illumina sequence reads generated from isolate CBS 139395 were mapped against the CBS 139394 genome assembly. The parameters used were a mismatch cost of $2 \mathrm{bp}$, insertion and deletion cost of $3 \mathrm{bp}$, and 0.5 and $0.8 \mathrm{bp}$ for length and similarity fraction, respectively. The CLC Genomics Workbench probabilistic variant detector was used to identify variant sites between the two organisms, with ploidy level set to one, nonspecific matches ignored, minimum coverage $=10$, and variant significance threshold set to $>0.90$. Species-level identifications were performed through concatenated phylogenetic analysis of four loci (ITS, TUB2, calmodulin [CAL], and HIS3) mined from the genome assembly of CBS 139394, as previously described (Gehesquière et al. 2016).

The whole-genome shotgun project of Calonectria pseudonaviculata CBS 139394 is deposited in the National Center for Biotechnology Information (NCBI) GenBank under accession number JYJY00000000, with version JYJY00000000 described in this article. TUB2 nucleotide sequences are deposited in NCBI GenBank under accession numbers KR011241 to KR011242.

\section{Results}

Disease symptoms. In September 2014, symptoms consistent with boxwood blight disease were observed on European boxwood planted the previous spring in a residential landscape in Baltimore County, MD (Fig. 1A; Supplementary Fig. S1). Sarcococca planted at the same time in the same landscape bed as the blighted boxwood shrubs also exhibited disease symptoms; these included twig dieback and dark lesions on leaves and stems (Fig. 1 A to D). It was unknown
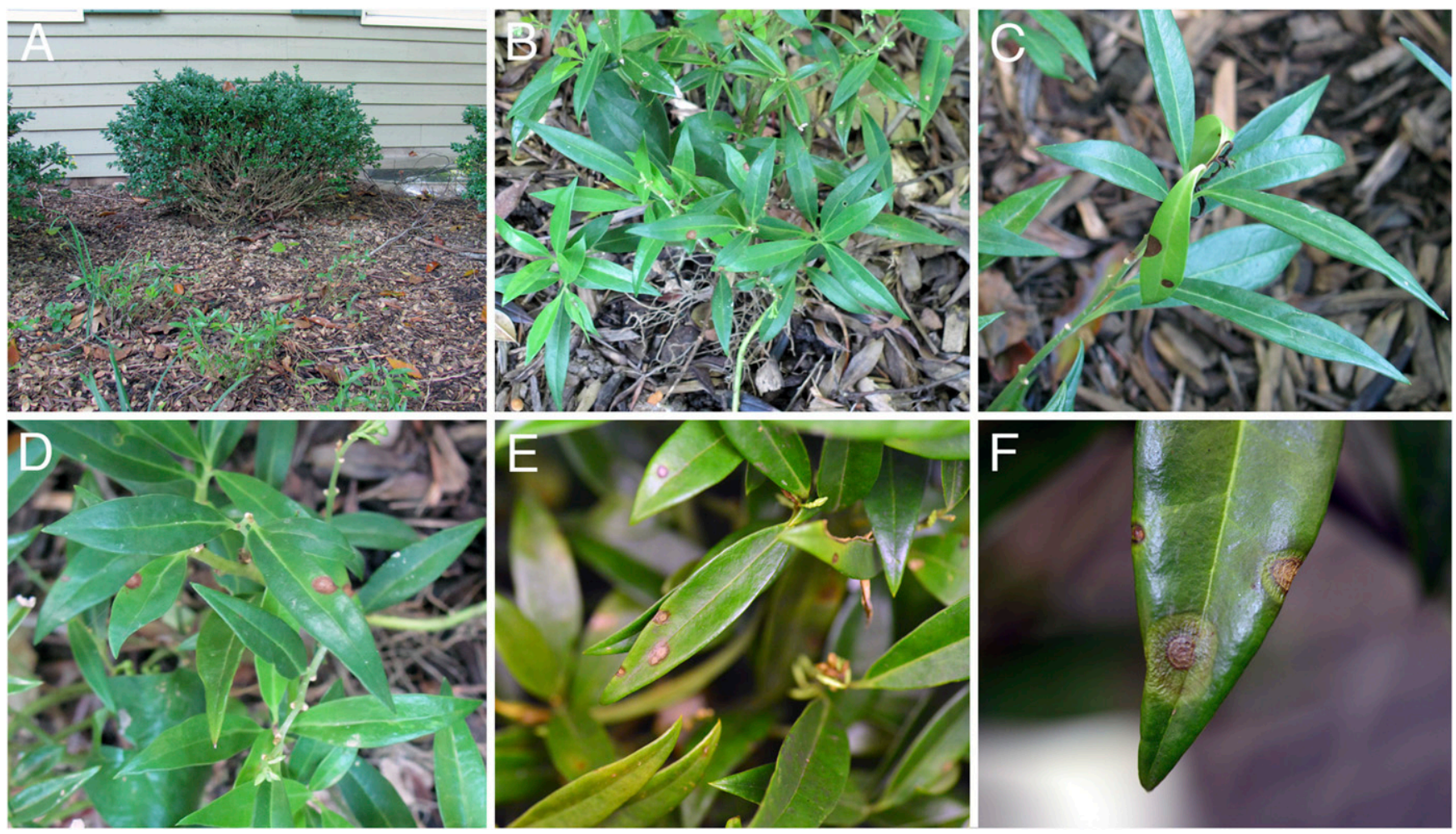

Fig. 1. Disease symptoms of Calonectria pseudonaviculata on Sarcococca hookeriana. A to D, Sarcococca plants located next to infected Buxus sempervirens showing blight symptoms in a residential landscape in Maryland. E and F, Leaf lesions and twig dieback induced by C. pseudonaviculata on inoculated S. hookeriana Fragrant Valley plants at 10 days postinoculation. 
whether the disease found on sarcococca was related to the blight symptoms on boxwood. In general, diseased sarcococca plants were smaller and less robust compared with uninfected plants. No previous reports of these symptoms on Sarcococca spp. were found in the literature (Farr and Rossman 2015). In fact, to the best of our knowledge, this was the first incidence of any disease reported from $S$. hookeriana worldwide and only the second disease sighting from any species of Sarcococca in the United States (Farr and Rossman 2015).

Morphological observations and pathogenicity tests. Initial observation of diseased sarcococca and boxwood plants showed the presence of characteristic conidiophores and conidia consistent with those described from the genus Calonectria, suggesting that both hosts might be infected by the same pathogen. Fungal structures were observed on the undersides of leaf lesions and the surface of dead twigs on both sarcococca and boxwood plants. Similarly, when grown in axenic culture, fungi isolated from both hosts exhibited colony morphologies consistent with those described for the genus Calonectria (Henricot and Culham 2002). Both fungal isolates grew as puffy colonies on PDA, with the center of the colony light to dark brown and edges white, reaching 34 to $37 \mathrm{~mm}$ at $7 \mathrm{dpi}$ (Fig. $2 \mathrm{~A}$ to D). A summary of morphological features observed from the cultured fungal isolates is presented in Table 1. For CBS 139394, stipes were usually septate ( 93 to $137 \mu \mathrm{m}$ long; $\bar{x}=119$ by $5 \mu \mathrm{m}$ ) and hyaline, terminating in a broadly ellipsoidal vesicle with a papillate apex (6 to $10 \mu \mathrm{m}$ in diameter). Phialides were doliiform to reniform, hyaline, aseptate, 9 to 19 by 2 to $5 \mu \mathrm{m}(\bar{x}=14$ by $4 \mu \mathrm{m})$; apex with minute periclinal thickening and inconspicuous collarette. Conidia were cylindrical with rounded ends, 43 to 57 by 3 to $6 \mu \mathrm{m}(\bar{x}=52$ by

Table 1. Summary of morphological features of Calonectria pseudonaviculata isolates collected from infected Sarcococca hookeriana (CBS 139394) and Buxus sempervirens plants (CBS 139395)

\begin{tabular}{lrr}
\hline & \multicolumn{2}{c}{ Isolate $^{\mathbf{a}}$} \\
\cline { 2 - 3 } Structure $(\boldsymbol{\mu m})$ & CBS 139394 & CBS 139395 $^{\mathbf{a}}$ \\
\hline Conidia & 52 & 48 \\
$\quad$ Length & 5 & 6 \\
$\quad$ Diameter & 14 & 14 \\
Phialides & 4 & 5 \\
$\quad$ Length & & \\
$\quad$ Diameter & 119 & 115 \\
Stipes & 5 & 5 \\
$\quad$ Length & & 8 \\
$\quad$ Diameter & 8 & \\
Vesicles & & \\
Diameter & & \\
\hline
\end{tabular}

a All values represent the mean of 30 units per structure.
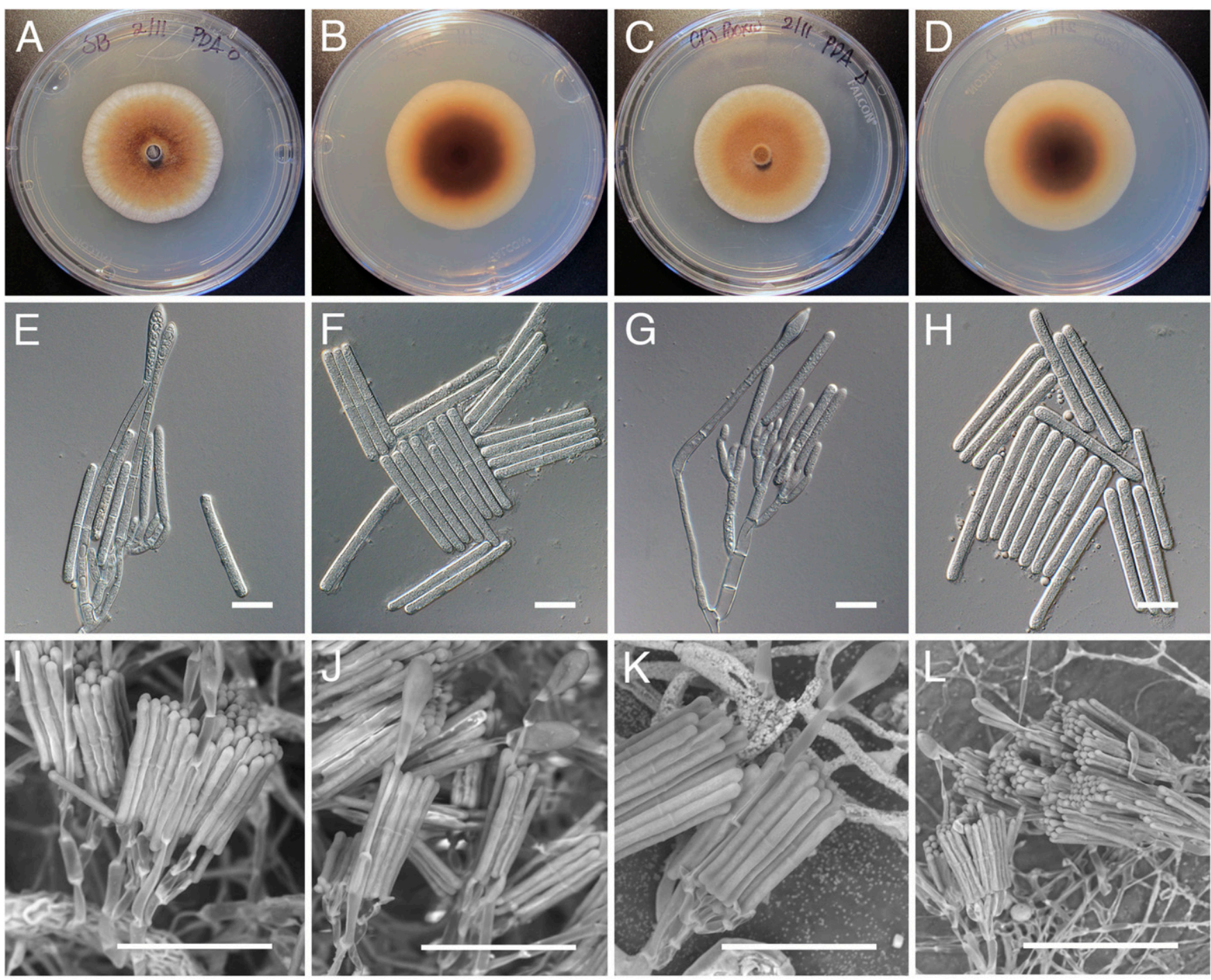

Fig. 2. Morphological observations of Calonectria pseudonaviculata isolated from diseased Sarcococca hookeriana var. humilis (sarcococca) and Buxus sempervirens var. joy (boxwood). A and B, Sarcococca isolate CBS 139394 and C and D, boxwood isolate CBS 139394 colonies on potato dextrose agar. E and F, Sarcococca isolate CBS 139394 and $\mathbf{~}$ and $\mathbf{H}$, boxwood isolate CBS 139394 conidiophores, vesicles, and macroconidia. I and J, Sarcococca isolate CBS 139394 and K and L, boxwood isolate CBS 139394 scanning electron microscopy of conidiophores, vesicles, and macroconidia. Scale bar: $\mathrm{E}$ to $\mathrm{H}=20 \mu \mathrm{m} ; \mathrm{I}, \mathrm{J}$, and $\mathrm{L}=100 \mu \mathrm{m} ;$ and $\mathrm{K}=50 \mu \mathrm{m}$. 
$5 \mu \mathrm{m}), 1$ septate, lacking a visible abscission scar, held in parallel cylindrical clusters in a colorless slime (Fig. $2 \mathrm{E}$ and F). No morphological differences between CBS 139394 and CBS 139395 were observed (Fig. 2; Table 1). SEM images showed mycelia of both isolates growing tightly along the surface of boxwood leaves. Branching hyphae gave origin to abundant asexual reproductive structures, with stipes, vesicles, conidiophores, phialides, and conidia growing upward from the surface of the plant leaf (Fig. 2I to L). Based on morphological characteristics (Henricot et al. 2000), the fungal isolates infecting the diseased sarcococca and boxwood plants were both identified as members of the genus Calonectria.

In order to confirm pathogenicity of the Calonectria isolate collected from sarcococca, healthy sarcococca plants were inoculated with a conidial suspension of CBS 139394. Small necrotic leaf spots, similar to those observed from the original sarcococca, were observed on inoculated plants at $7 \mathrm{dpi}$, and enlarged to 7 to $10 \mathrm{~mm}$ in diameter after 10 dpi (Fig. 1E and F). Symptomatic leaves dropped from the plants within 3 weeks postinoculation. Leaves with spots were incubated under moist condition for $24 \mathrm{~h}$ and conidiophores and conidia of Calonectria spp. developed on the undersides of necrotic lesions. The genus Calonectria was reisolated from infected tissue. No signs of the fungus or disease symptoms were observed from negative control plants.

TUB2 sequence analysis. To expand on morphological diagnoses, a 358-bp fragment of the TUB2 gene was sequenced from CBS 139394 and CBS 139395, as has been previously used to describe new outbreaks of boxwood blight disease (Ivors et al. 2012; Malapi-Wight et. al 2014a). DNA sequences of TUB2 from the two Calonectria isolates shared $100 \%$ nucleotide identity. BLASTn searches of the NCBI GenBank nr database showed that the TUB2 sequences shared 99 to $100 \%$ nucleotide identity with previously characterized isolates of $C$. pseudonaviculata, including recent collections of the fungus isolated from the mid-Atlantic region of the United States (e.g., accessions KF785808 to KF785811) (MalapiWight et al. 2014a). The TUB2 sequences also shared $99 \%$ nucleotide identity with sequences of $C$. henricotiae (e.g., accession JX535308) (Gehesquière et al. 2013). These results, along with the morphological characteristics, confirmed that Calonectria fungi were associated with the diseased sarcococca and boxwood plants; however, species-level diagnosis could not be completed from these data.

Genome sequencing and variant analysis. To identify the Calonectria isolates to species level and determine the genetic variation between them, DNA from isolates CBS 139394 and CBS 139395 was used to generated NGS reads using Illumina technology. A draft genome sequence of CBS 139394 from sarcococca was de novo assembled, as summarized in Table 2. The estimated genome size was $51.4 \mathrm{Mb}$, with an average read depth of coverage of 70.4-fold and 13,103 predicted gene models. The CBS 139394 genome assembly contained complete copies of $93.6 \%$ of the CEGMA ultraconserved eukaryotic gene set and partial copies of $96.4 \%$ of the CEGMA gene set. Sequence analysis of the ITS, TUB2, CAL, and HIS3 regions of the genome $(523,517,412$, and $424 \mathrm{bp}$, respectively; $1,876 \mathrm{bp}$ total) identified both Calonectria isolates as C. pseudonaviculata, with the resultant phylogenetic tree (Supplementary Fig. S2) structured as previously reported (Gehesquière et al. 2016). C. pseudonaviculata isolates CBS 139394 and CBS 139395 shared 100\% sequence identity at these four loci.

To determine the similarity between sarcococca isolate CBS 139394 and boxwood isolate CBS 139395 on the whole-genome scale, we generated 12,030,404 paired-end Illumina sequence reads (average length $=284.1 \mathrm{bp}$ ) from CBS 139395, and mapped 99.5\% of the reads against the CBS 139394 genome assembly. Probabilistic variant analysis identified just one single-nucleotide polymorphism (SNP; G/C) that distinguished between the 51.4 million nucleotide sites found in the genomes of CBS 139394 and CBS 139395 (1.95-10\% difference; Table 2). The SNP was located in CBS 139394 contig 261, where it was present at a read depth coverage of $44 \times$ in both genomes. The SNP was present within an intergenic region, located between genes encoding a putative amidohydrolase and a hypothetical protein.

\section{Discussion}

In this study, we describe a new disease of S. hookeriana, for which we propose the common name of sarcococca blight. To our knowledge, this disease represents the first report of $C$. pseudonaviculata inducing disease on this host, the first incidence of any disease of $S$. hookeriana worldwide, and only the second report of a disease affecting any species of Sarcococca in the United States (Farr and Rossman 2015). This report marks the third host genus in the Buxaceae family with demonstrated susceptibility to $C$. pseudonaviculata infection: Buxus, Pachysandra, and Sarcococca. Previous experiments by Henricot and colleagues (2008) showed that three $C$. pseudonaviculata isolates from boxwood could colonize detached leaves of an unnamed Sarcococca sp. and produce leaf spots and conidia, albeit at low levels. The authors proposed these reduced sporulation levels as a possible mechanism for the observed resistance of sarcococca to the pathogen in the field (Henricot et al. 2008). Sarcococca's resistance to C. pseudonaviculata is longstanding in the United Kingdom and continental Europe, where the fungus has been present for over 20 years in some regions. Therefore, it is somewhat surprising to see $C$. pseudonaviculata so quickly expand its natural host range in the United States a mere 3 years after the pathogen was first observed in North America (Ivors et al. 2012) — not just once, but two times in as many years. Previously, another host expansion by C. pseudonaviculata occurred when plants in the genus Pachysandra were infected by the pathogen in Connecticut during 2012 (La Mondia et al. 2012). The factors facilitating these novel natural infections of two new plant genera in the landscape are unknown. A disease is controlled not only by genetic traits of the pathogen but also by the other two components of the disease triangle- the environment and host-and changes to any one or more of these components may have led to the pathogen's rapid host range expansion in the United States. Physical proximity of the hosts cannot independently account for the host adaptation, because all three host genera are commonly grown together in landscapes and nurseries throughout the United Kingdom and continental Europe. Differences in environmental factors may offer an explanation but this would require testing. It is also conceivable that the cultivars and varieties of sarcococca, pachysandra, and boxwood grown in the

Table 2. Summary of the draft de novo genome assembly of Calonectria pseudonaviculata CBS 139394, and the read mapping of C. pseudonaviculata isolate CBS 139395 to the CBS 139394 assembly

\begin{tabular}{lc}
\hline Assembly & Number \\
\hline Reads & \\
Total read count & $12,995,114$ \\
Reads in pairs & $12,947,662$ \\
Average read length & 283.2 \\
Scaffolds & \\
$\mathrm{N}_{50}$ & 121,364 \\
$\mathrm{~N}_{75}$ & 60,104 \\
$\mathrm{~L}_{50}$ & 119 \\
$\mathrm{~L}_{75}$ & 270 \\
Max. length & 591,266 \\
Average length & 36,749 \\
Scaffold $>1 \mathrm{~Kb}$ & 1,340 \\
Scaffold $>5 \mathrm{~Kb}$ & 764 \\
Scaffold $>100 \mathrm{~Kb}$ & 153 \\
Number & 1,903 \\
Genome size & \\
Size (Mb) & 51.4 \\
Coverage (fold) & 70.4 \\
G +C content (\%) & 47.86 \\
CEGMA & $93.55 \%$ \\
Number of genes & 13,103 \\
Nucleotide variants, CBS 139394 vs. CBS 139395 & 1 \\
Total & G/C \\
SNP & 261 \\
Contig \# & Intergenic \\
Location & \\
\hline
\end{tabular}


United States are not equivalent to those found in Europe. Almost no information about the genetics of the Buxaceae family is available, although recent efforts aimed at breeding boxwood with resistance to blight may provide the resources needed to address this possibility at some later date (Thammina et al. 2014; Van Laere et al. 2011). On the pathogen end, there is very little to indicate substantive genetic variation between the $C$. pseudonaviculata isolates from sarcococca and boxwood. Only a unique SNP located within a non-protein-coding region differentiates between the approximately 51 million nucleotides in the genomes of the two host isolates. Broadly speaking, this indicates that the same C. pseudonaviculata genotype has the ability to induce disease on both plant species. However, mutations on intergenic regions, such as those found adjacent to cis regulatory elements, may have a profound effect on an organism's biology through their influence on gene expression (Cirulli and Goldstein 2010). For example, in the human cancer HeLa cell line, viral replication activates promoters for gene transcription by a physical communication with other cis regulatory elements located hundreds of nucleotides away. Mutations on these intergenic regions repress the physical interactions between proteins, resulting in a lack of transcription activation (Nolis et al. 2009). In fungal plant pathogens, the importance of noncoding regions has also been demonstrated (Raffaele and Kamoun 2012). For instance, Rech and colleagues (2014) identified an abundance of mutations at the $5^{\prime}$ untranslated regions of genes coding for effector proteins in several Colletotrichum graminicola isolates. The authors suggested that this display of polymorphisms was the consequence of natural selection that conferred enhanced virulence (Rech et al. 2014). Alternatively, given the fact that Calonectria pseudonaviculata is only capable of reproducing clonally in North America due to the presence of just one mating type (Malapi-Wight et al. 2014b), the diagnostic SNP may represent nothing more than a spontaneous mutation without adaptive value that has arisen through random genetic drift. Future work is needed to determine whether the SNP present in C. pseudonaviculata CBS 139394 has a regulatory effect and whether the de novo mutation is the underlying cause of some new pathogenicity trait.

To our knowledge, this study marks the first direct application of WGS and NGS as a diagnostic tool to identify the causal agent of a new fungal disease. Outside of virology, plant pathologists have yet to embrace the power of NGS technology for disease diagnostic purposes, despite the availability of extensive genomic resources for fungi and bacteria. In contrast, genomics-based NGS approaches are now routinely used for the identification of human and animal diseases and genetic disorders, with diagnoses now possible for a broad range of clinical conditions (Hoffmann et al. 2012; Need et al. 2012; Sherry et al. 2013; Thorburn et al. 2015; Worthey et al. 2011). The advantages of an NGS approach for diagnostics are numerous. With the sheer quantity of data produced using NGS platforms, as shown in the current study, complete genome sequence assemblies can take the place of individual molecular markers, yielding massive increases in discriminatory power, even in the absence of any existing taxonomic or population genetic resources. For example, in the current study, standard markers could not have identified the single polymorphic site that differentiated the two host isolates. Another benefit imparted by NGS is the universality of the reagents for work involving eukaryotic DNA. Because the NGS reagents used for sequencing are the same regardless of the source of the eukaryotic gDNA, there is no need to inventory multiple diagnostic assays, undergo specialized training for several diagnostic assays, or purchase and wait for the delivery of specialized assay reagents. Instead, reagent inventory is limited to a core set of NGS reagents, and analyses could proceed as soon as DNA was available. With the increasing availability of user-friendly benchtop NGS equipment such as the Illumina MiSeq and MiniSeq and Thermo Fisher's Ion Torrent, and automated NGS library preparation instruments such as the Illumina NeoPrep, necessary skills could be acquired by technical staff and student trainees. In the present study, the turnaround time for inhouse sequencing library preparation (manual library preparation), sequencing on the Illumina MiSeq instrument, and bioinformatics analyses using CLC Genomics GUI software was less than 1 week. This short turnaround time was possible due to the fact that analyses were executed under optimal conditions, where trained staff members with NGS and skills using the software were available in-house. Diagnostics using standard amplification-based markers would require roughly the same amount of time and, as we found from our analysis of the TUB2 amplicon, provide substantially less informative data. Existing endpoint real-time PCR assays capable of discriminating C. pseudonaviculata from $C$. henricotiae could have been completed in a similar time frame but only after specialized TaqMan assay reagents were ordered and received, which could take between 2 and 4 weeks and incur reagent costs of approximately $\$ 400$ to $\$ 600$.

As with any new technology, there are many potential disadvantages and hurdles to overcome in the development of practical NGS-based diagnostic pipelines. Access to instrumentation, reagent costs, and bioinformatics expertise are all legitimate concerns. As discussed in the introduction to this article, molecular diagnostics of any form may not be feasible in the diagnostic setting for numerous reasons, although the use of NGS approaches may overcome some of the issues. In the present study, we acknowledge that our analyses of the sarcococca and boxwood pathogens were performed under ideal conditions, where in-house instrumentation and expertise were readily available. Furthermore, the nature of the disease outbreak did not present any urgent time constraints. These conditions are not likely to reflect most diagnostic laboratory settings. Indeed, neither of the two diagnosticians authoring this article have inhouse NGS capability but the partnership between diagnosticians and researchers enabled us to carry out the identifications jointly. Continual development of new NGS platforms, such as the MinION nanopore and Illumina MiniSeq instrumentation (Karlsson et al. 2015), may ultimately lead to greater access to in-house instruments and increasingly affordable reagents. The costs associated with NGS are rapidly decreasing; however, they are still unquestionably higher than those associated with Sanger sequencing or real-time PCR. This represents one of the greatest barriers for NGS implementation in everyday diagnostic settings, and may preclude adoption by diagnosticians except for the most high-impact pathogens. As an example, in the present study, our reagent costs on the Illumina MiSeq platform were $\$ 700$ per genome (without including personnel salaries and cost of equipment), at a relatively high depth of coverage (70x). Similarly, in a medical setting, researchers using the Ion Torrent benchtop NGS instrument reported a reagent cost of $\$ 300$ per strain of Escherichia coli $(22$ to $67 \times$ coverage) (Sherry et al. 2013).

Developing an NGS workflow is critical, involves massive quantities of data, and presents another barrier to the use of NGS in diagnostic settings. Computational capacity can be a limiting factor, especially when confronted with organisms with large or complex genomes. In our analyses, the organism of interest was an ascomycete fungus with a relatively average-sized haploid genome (51.4 Mb) (Tavares et al. 2014) and little repetitive DNA to complicate the analysis (data not shown). However, because fungal genomes display a range of possible sizes and ploidy levels, a priori size prediction is not always possible. For example, Puccinia chrysanthemi possesses an 806.5-Mb size genome (Tavares et al. 2014), the genome of Uromyces bidentis is $2,489 \mathrm{Mb}$ (Ramos et al. 2015), Rhizoctonia solani has an average of eight nuclei per cell (Hane et al. 2014), and Colletotrichum genomes display a range of sizes depending on the quantity of repetitive DNA present (Crouch et al. 2014). These traits all increase the difficulty of de novo genome assembly and variant analyses. The expertise required to analyze these data are not a minor factor. However, growing availability of biologist-friendly bioinformatics packages are increasingly facilitating genome-scale analyses for biologists without extended computer programming knowledge (Massart et al. 2014).

The comparative genomics approach utilized in this research identified just one SNP that differentiated the two host isolates of C. pseudonaviculata. Ideally, if the disease outbreak warranted further investigation, we might have gone back to the two commercial nurseries where the plants were originally purchased and performed the same NGS analysis from diseased plants at both sites to screen for 
the presence or absence of the diagnostic SNP. In the current study, this trace-back was not easily undertaken and, given the economics involved in this particular disease outbreak, was not a desirable financial outlay. However, under different circumstances, particularly for high-risk pathogens, this technology has the potential to become an integral part of pathogen intervention strategies, allowing precise real-time tracking of the origin and spread of epidemics. In the absence of robust population genetic data, for newly emergent fungal pathogens where no a priori information is available, it generally takes years to generate equivalent datasets using traditional markerbased approaches. In contrast, NGS provides a high-resolution tool that could offer diagnostic laboratories and regulatory personnel the unprecedented ability to quickly respond to emerging infectious diseases and unexpected pathogen variants. As NGS approaches move into mainstream use as diagnostic tools, the technology may also play a central role in risk assessment and the development of regulatory policies based on evidence-driven research.

\section{Acknowledgments}

This research was funded by 2013-2015 USDA Animal and Plant Health Inspection Service Plant Protection and Quarantine (APHIS-PPQ) Farm Bill grants and USDA-ARS Floriculture and Nursery Initiative funding to J. A. Crouch, and USDA-ARS project 8042-22000-279; M. Malapi-Wight was supported by a class of 2013 USDA-ARS Headquarters Research Associate fellowship to J. A. Crouch; C. Salgado-Salazar was supported by 2014-2015 USDA-APHIS-PPQ Farm Bill grants to J. A. Crouch; and J. E. Demers was supported by a class of 2013 USDA-ARS Headquarters Research Associate fellowship to L. Castlebury. We thank A. Gould for her continued partnership and support and for her ongoing mentorship of C. Salgado-Salazar.

\section{Literature Cited}

Adams, I. P., Glover, R. H., Monger, W. A., Mumford, R., Jackeviciene, E., Navalinskiene, M., and Boonham, N. 2009. Next-generation sequencing and metagenomic analysis: A universal diagnostic tool in plant virology. Mol. Plant Pathol. 10:537-545.

Ash, G. J., Lang, J. M., Triplett, L. R., Stodart, B. J., Verdier, V., Vera Cruz, C., Rott, P., and Leach, J. E. 2014. Development of a Genomics-Based LAMP (loop-mediated isothermal amplification) assay for detection of Pseudomonas fuscovaginae from rice. Plant Dis. 98:909-915.

Barba, M., Czosnek, H., and Hadidi, A. 2014. Historical perspective, development and applications of next-generation sequencing in plant virology. Viruses 6 : 106-136.

Bellemain, E., Carlsen, T., Brochmann, C., Coissac, E., Taberlet, P., and Kauserud, H. 2010. ITS as an environmental DNA barcode for fungi: An in silico approach reveals potential PCR biases. BMC Microbiol. 10:189.

Boonham, N., Kreuze, J., Winter, S., van der Vlugt, R., Bergervoet, J., Tomlinson, J., and Mumford, R. 2014. Methods in virus diagnostics: From ELISA to next generation sequencing. Virus Res. 186:20-31.

Bühlmann, A., Pothier, J. F., Tomlinson, J. A., Frey, J. E., Boonham, N., Smits, T. H. M., and Duffy, B. 2013. Genomics-informed design of loop-mediated isothermal amplification for detection of phytopathogenic Xanthomonas arboricola pv. pruni at the intraspecific level. Plant Pathol. 62:475-484.

Cirulli, E. T., and Goldstein, D. B. 2010. Uncovering the roles of rare variants in common disease through whole-genome sequencing. Nat. Rev. Genet. 11: 415-425.

Crouch, J. A., Clarke, B. B., and Hillman, B. I. 2009a. What is the value of ITS sequence data in Colletotrichum systematics and species diagnosis? A case study using the graminicolous Colletotrichum group. Mycologia 101:648-656.

Crouch, J. A., Clarke, B. B., White, J. F., Jr., and Hillman, B. I. 2009b. Systematic analysis of the graminicolous Colletotrichum and a description of six new species from warm season grasses. Mycologia 101:717-732.

Crouch, J. A., O'Connell, R., Gan, P., Buite, E., Torres, M. F., Beirn, L. A., Shirasu, K., and Vaillancourt, L. J. 2014. Genomics of Colletotrichum. Pages 69-102 in: Genomics of Plant-Associated Fungi: Monocot Pathogens. A. L. Park, R. Dean, and C. Kole, eds. Springer-Verlag, Berlin Heidelberg, Germany.

Crouch, J. A., Tredway, L. P., Clarke, B. B., and Hillman, B. I. 2009c. Phylogenetic and population genetic divergence correspond with habitat for the pathogen Colletotrichum cereale and allied taxa across diverse grass communities. Mol. Ecol. 18:123-135.

Crous, P. W. 2009. Taxonomy and phylogeny of the genus Mycosphaerella and its anamorphs. Fungal Divers. 38:1-24.

Damm, U., Woudenberg, J. H. C., Cannon, P. F., and Crous, P. W. 2009. Colletotrichum species with curved conidia from herbaceous hosts. Fungal Divers. 39:45-87.

Dart, N. L., and Hong, C. 2013. Significance of soil inoculum in the epidemiology of boxwood blight caused by Calonectria pseudonaviculata. Phytopathology 103:33-34.

Farr, D. F., and Rossman, A. Y. 2015. Fungal Databases, Systematic Mycology and Microbiology Laboratory. Online publication. United States Department of
Agriculture-Agricultural Research Service. http://nt.ars-grin.gov/fungalDatabases/ index.cfm

Gehesquière, B., Crouch, J. A., Marra, R. E., Van Poucke, K., Rys, F., Maes, M., Gobin, B., Hofte, M., and Heungens, K. 2016. Characterization and taxonomic re-assessment of the box blight pathogen Calonectria pseudonaviculata, introducing Calonectria henricotiae sp. nov. Plant Pathol. 65:37-52.

Gehesquière, B., D’Haeyer, S., Pham, K. T. K., Van Kuik, A. J., Maes, M., Hofte, M., and Heungens, K. 2013. qPCR assays for the detection of Cylindrocladium buxicola in plant, water, and air samples. Plant Dis. 97:1082-1090.

Glass, N. L., and Donaldson, G. C. 1995. Development of primer sets designed for use with the PCR to amplify conserved genes from filamentous ascomycetes. Appl. Environ. Microbiol. 61:1323-1330.

Hane, J. K., Anderson, J. P., Williams, A. H., Sperschneider, J., and Singh, K. B. 2014. Genome sequencing and comparative genomics of the broad host-range pathogen Rhizoctonia solani AG8. PLoS Genet. 10:e1004281.

Harder, C. B., Laessoe, T., Froslev, T. G., Ekelund, F., Rosendahl, S., and Kjoller, R. 2013. A three-gene phylogeny of the Mycena pura complex reveals 11 phylogenetic species and shows ITS to be unreliable for species identification. Fungal Biol. 117:764-775.

Henricot, B., and Culham, A. 2002. Cylindrocladium buxicola, a new species affecting Buxus spp., and its phylogenetic status. Mycologia 94:980-997.

Henricot, B., Gorton, C., Denton, G., and Denton, J. 2008. Studies on the control of Cylindrocladium buxicola using fungicides and host resistance. Plant Dis. 92: 1273-1279.

Henricot, B., Sierra, A. P., and Prior, C. 2000. A new blight disease on Buxus in the UK caused by the fungus Cylindrocladium. Plant Pathol. 49:805.

Hoffmann, B., Scheuch, M., Höper, D., Jungblut, R., Holsteg, M., Schirrmeier, H., Eschbaumer, M., Goller, K. V., Wernike, K., Fisher, M., Breithaupt, A., Mettenleiter, T. C., and Beer, M. 2012. Novel orthobunyavirus in cattle, Europe, 2011. Online publication. Emerg. Infect. Dis. 18.

Ivors, K. L., Lacey, L. W., Milks, D. C., Douglas, S. M., Inman, M. K., Marra, R. E., and LaMondia, J. A. 2012. First report of boxwood blight caused by Cylindrocladium pseudonaviculatum in the United States. Plant Dis. 96:1070.

Karlsson, E., Lärkeryd, A., Sjödin, A., Forsman, M., and Stenberg, P. 2015. Scaffolding of a bacterial genome using MinION nanopore sequencing. Sci. Rep. 5:11996.

Kehoe, M. A., Coutts, B. A., Buirchell, B. J., and Jones, R. A. C. 2014. Plant virology and next generation sequencing: Experiences with a Potyvirus. PLoS One 9:e104580.

LaMondia, J. A., Li, D. W., Marra, R. E., and Douglas, S. M. 2012. First report of Cylindrocladium pseudonaviculatum causing leaf spot of Pachysandra terminalis. Plant Dis. 96:1069.

Lawrence, D. P., Gannibal, P. B., Peever, T. L., and Pryor, B. M. 2013. The sections of Alternaria: Formalizing species-group concepts. Mycologia 105: 530-546.

Luo, J., Qiu, H., Cai, G., Wagner, N. E., Bhattacharya, D., and Zhang, N. 2015. Phylogenomic analysis uncovers the evolutionary history of nutrition and infection mode in rice blast fungus and other Magnaporthales. Sci. Rep. 5: 9448.

MacDiarmid, R., Rodoni, B., Melcher, U., Ochoa-Corona, F., and Roosinck, M. 2013. Biosecurity implications of new technology and discovery in plant virus research. PLoS Pathog. 9:e1003337.

Malapi-Wight, M., Hebert, J. B., Buckley, R., Daughtrey, M. L., Gregory, N. F., Rane, K., Tirpak, S., and Crouch, J. A. 2014a. First report of boxwood blight caused by Calonectria pseudonaviculata in Delaware, Maryland, New Jersey, and New York. Plant Dis. 98:698.

Malapi-Wight, M., Hebert, J. B., Rivera, Y., Ismaiel, E., Saied, N., Gehesquière, B., Heungens, K., and Crouch, J. A. 2014b. Comparative genomics in the boxwood blight system: Insights into the global diversity of the mating-type locus. (Abstr.) Phytopathology 104:S74.

Malapi-Wight, M., Salgado-Salazar, C., Demers, J., Veltri, D., and Crouch, J. A. 2015. Draft genome sequence of Dactylonectria macrodidyma, a plant pathogenic fungus in the Nectriaceae. Genome Announc. 3:e00278-15.

Manamgoda, D. S., Rossman, A. Y., Castlebury, L. A., Crous, P. W., Madrid, H., Chukeatirote, E., and Hyde, K. D. 2014. The genus Bipolaris. Stud. Mycol. 79: 221-88.

Massart, S., Olmos, A., Jijakli, H., and Candresse, T. 2014. Current impact and future directions of high throughput sequencing in plant virus diagnostics. Virus Res. 188:90-96.

Miller, S. A., Beed, F. D., and Harmon, C. L. 2009. Plant disease diagnostic capabilities and networks. Annu. Rev. Phytopathol. 47:15-38.

Need, A. C., Shashi, V., Hitomi, Y., Schoch, K., Shianna, K. V., McDonald, M. T., Meisler, M. H., and Goldstein, D. B. 2012. Clinical application of exome sequencing in undiagnosed genetic conditions. J. Med. Genet. 49:353-361.

Nolis, I. K., McKay, D. J., Mantouvalou, E., Lomvardas, S., Merika, M., and Thanos, D. 2009. Transcription factors mediate long-range enhancerpromoter interactions. Proc. Natl. Acad. Sci. USA 106:20222-20227.

O’Donnell, K., Ward, T. J., Geiser, D. M., Kistler, H. C., and Aoki, T. 2004. Genealogical concordance between the mating type locus and seven other nuclear genes supports formal recognition of nine phylogenetically distinct species within the Fusarium graminearum clade. Fungal Genet. Biol. 41: 600-623. 
Parra, G., Bradnam, K., and Korf, I. 2007. CEGMA: A pipeline to accurately annotate core genes in eukaryotic genomes. Bioinformatics 23:1061-1067.

Raffaele, S., and Kamoun, S. 2012. Genome evolution in filamentous plant pathogens: Why bigger can be better. Nat. Rev. Microbiol. 10:417-430.

Ramos, A. P., Tavares, S., Tavares, D., Silva, M. D., Loureiro, J., and Talhinhas, P. 2015. Flow cytometry reveals that the rust fungus, Uromyces bidentis (Pucciniales), possesses the largest fungal genome reported-2489 Mbp. Mol. Plant Pathol. 16:1006-1010.

Rayner, R. 1970. A Mycological Colour Chart. Commonwealth Mycological Institute, Kew, Surrey, UK.

Rech, G. E., Sanz-Martin, J. M., Anisimova, M., Sukno, S. A., and Thon, M. R. 2014. Natural selection on coding and noncoding DNA sequences is associated with virulence genes in a plant pathogenic fungus. Genome Biol. Evol. 6:2368-2379.

Sherry, N. L., Porter, J. L., Seemannd, T., Watkins, A., Stinear, T. P., and Howden, B. P. 2013. Outbreak investigation using high-throughput genome sequencing within a diagnostic microbiology laboratory. J. Clin. Microbiol. 51:1396-1401.

Stanke, M., Diekhans, M., Baertsch, R., and Haussler, D. 2008. Using native and syntenically mapped cDNA alignments to improve de novo gene finding. Bioinformatics 24:637-644.

Tavares, S., Ramos, A. P., Pires, A. S., Azinheira, H. G., Caldeirinha, P., Link, T., Abranches, R., Silva, M. C., Voegele, R. T., Loureiro, J., and Talhinhas, P. 2014. Genome size analyses of Pucciniales reveal the largest fungal genomes. Front. Plant Sci. 5:422.
Thammina, C. S., Olsen, R. T., Malapi-Wight, M., Crouch, J. A., and Pooler, M. 2014. Development of polymorphic genic-SSR markers by cDNA library sequencing in boxwood, Buxus spp. (Buxaceae). Appl. Plant Sci. 2:1400095.

Thorburn, F., Bennett, S., Modha, S., Murdoch, M., Gunson, R., and Murcia, P. R. 2015. The use of next generation sequencing in the diagnosis and typing of respiratory infections. J. Clin. Microbiol. 69:96-100.

Van Laere, K., Hermans, D., Leus, L., and van Huylenbroeck, J. 2011. Genetic relationships in European and Asiatic Buxus species based on AFLP markers, genome sizes and chromosome numbers. Plant Syst. Evol. 293:1-11.

Visscher, P. M., Brown, M. A., McCarthy, M. I., and Yang, J. 2012. Five years of GWAS discovery. Am. J. Hum. Genet. 90:7-24.

Weir, B. S., Johnston, P. R., and Damm, U. 2012. The Colletotrichum gloeosporioides species complex. Stud. Mycol. 73:115-180.

Worthey, E. A., Mayer, A. N., Syverson, G. D., Helbling, D., Bonacci, B. B. Decker, B., Serpe, J. M., Dasu, T., Tschannen, M. R., Veith, R. L., Basehore, M. J., Broeckel, U., Tomita-Mitchell, A., Arca, M. J., Casper, J. T., Margolis, D. A., Bick, D. P., Hessner, M. J., Routes, J. M., Verbsky, J. W., Jacob, H. J., and Dimmock, D. P. 2011. Making a definitive diagnosis: Successful clinical application of whole exome sequencing in a child with intractable inflammatory bowel disease. Genet. Med. 13:255-262.

Zhang, N., Zhao, S., and Shen, Q. 2011. A six-gene phylogeny reveals the evolution of mode of infection in the rice blast fungus and allied species. Mycologia 103:1267-1276. 